\title{
Reproductive outcome among female hairdressers
}

\author{
L Rylander, A Axmon, K Torén, M Albin
}

Occup Environ Med 2002;59:517-522

See end of article for authors' affiliations .....................

Correspondence to: Associate Professor L Rylander, Department of Occupational and Environmental Medicine, Institute of Laboratory Medicine, University Hospital, SE-221 85 Lund, Sweden;

lars.rylander@ymed.lu.se

Accepted

13 February 2002

\begin{abstract}
Background: Working as a hairdresser involves exposure to a variety of chemical agents.
Aims: To estimate the risk of such exposure in relation to reproductive outcome.

Methods: A cohort of hairdressers, certified in Sweden from 1970 onwards, and a referent cohort of women from the general population were established and linked to the Swedish Medical Birth Register for the period 1973 to 1994. In the cohort of hairdressers 3706 women gave birth to 6960 infants. The corresponding numbers among the referents were 3462 and 6629 . Questionnaires were sent to all hairdressers to obtain individual exposure data. The response rate was $65 \%$.

Results: Compared with the referents, the hairdressers more often gave birth to infants that were small for gestational age (SGA). In addition, a higher fraction of the infants born to a hairdresser had a major malformation $(2.8 \% \vee 2.1 \%)$. Frequent permanent waving and spraying tended to be associated with increased risk of having an SGA infant, whereas no clear association could be seen between the individual exposure assessments and malformation risk.

Conclusions: Results indicated that hairdressers have a slight increased risk of having intrauterine growth retarded infants and infants with major malformation compared with women from the general population. However, no clear associations were seen between individual exposure assessments and these outcomes.
\end{abstract}

$\mathrm{T}$ oday there are about 18000 working hairdressers in Sweden, of which $85 \%$ are women. Hairdressers constitute a major occupational group exposed to a wide range of products with potential reproductive toxicity. Their work involves exposure to a variety of chemical agents as a result of use of several hair products like shampoos, permanent wave solutions, hair dyes, and hair sprays. ${ }^{1}$ Reproductive toxic effects have been reported for some of these agents: in animals for selenium, ${ }^{23}$ some dye formulations, ${ }^{45}$ dibutylphthalate, ${ }^{6}$ ethylene glycol ethers, ${ }^{27}$ and lead acetate ${ }^{8}$; and in humans after exposure to organic solvents, ${ }^{910}$ nitrosamines, ${ }^{11}$ formaldehyde, ${ }^{32}$ and hexachlorophene. ${ }^{13}$ A wide range of effects were observed, such as loss of fertility, growth retardation, and congenital defects. Both dermal absorption and inhalation are relevant uptake routes for hairdressers. ${ }^{14}$ However, only a few epidemiological studies on reproductive risk among hairdressers have been performed, and the results are inconsistent. ${ }^{1}$

The aim of the present study was to estimate the risk of working as a hairdresser in relation to reproductive outcome, such as birth weight, gestational length, stillbirths, malformations, and gender ratio. For comparison, we used a cohort of women from the general population. The associations between individual exposure assessments among hairdressers and reproductive outcome were also estimated.

\section{METHODS}

\section{Cohort of hairdressers}

A cohort of hairdressers was established from lists of all women that were certified at the major hairdressing schools in Sweden from 1970 to 1995. Only hairdressers born in 1945 or later were included $(n=7202)$. In Sweden the training for hairdressing lasts three years. During the period between 1970 and 1993, the third year was spent practising in hairdressings salons. In 1993, the education was changed so that less time was spent in salons and the practice work was completed at the school.

\section{Referents}

For comparison, a referent cohort of 7353 women was created. They were frequency matched to the hairdressers by calendar year of birth, but otherwise were randomly selected from the registry of the total population in Sweden.

\section{Register linkage and reproductive outcomes studied}

Both cohorts were linked to the Swedish Medical Birth Register (MBR), which includes almost every infant born in Sweden since $1973 .{ }^{15}$ The MBR is based on copies of record forms for maternity health care, the delivery, and the paediatric examination of the newborn. Some of the variables in the MBR were not added until 1982, therefore some information, for example, maternal smoking habits in early pregnancy, is missing for infants born before 1982. There is, however, no information about the spouses in the MBR. The MBR contains information (coded as International Classification of Diseases, 8th revision) on all types of birth defects identified in the newborn period, including many minor and insignificant deviations. This information was further supplemented by data from the Swedish Registry of Congenital Malformations, which has a higher diagnostic precision than the MBR with respect to malformations. ${ }^{16}$ The study was approved by the Ethics Committee of Lund University.

During the period 1973-94, 3706 women in the cohort of hairdressers gave birth to 6960 infants (1.88 infants per woman). The corresponding numbers among the referents were 3462 and 6629 (1.91 infants per woman). The reproductive outcomes studied were gender ratio, low birth weight (LBW, $<2.5 \mathrm{~kg}$ ), preterm birth (<37 weeks), small for gestational age (SGA), ${ }^{17}$ stillbirths, early neonatal deaths (END, <7 days of age), all malformations, and major malformations (excluding minor malformations such as preauricular appendices, undescended testicles, unstable hip, and nevus).

\section{Questionnaires}

To obtain individual exposure data, questionnaires were sent to all women in the cohort of hairdressers. The response rate

Abbreviations: END, early neonatal death; LBW, low birth weight; MBR, Medical Birth Register; SGA, small for gestational age 


\begin{tabular}{|c|c|c|c|}
\hline & \multicolumn{2}{|c|}{ Hairdressers } & \multirow[b]{2}{*}{ Referents $\mathrm{n}(\%)$} \\
\hline & All n (\%) & Questionnaire $\mathrm{n}(\%)$ & \\
\hline Infants born & 6960 & 4465 & 6629 \\
\hline Women given birth & 3706 & 2410 & 3462 \\
\hline \multicolumn{4}{|c|}{ Calendar year of birth } \\
\hline $1973-77$ & $830(12)$ & 486 (11) & 722 (11) \\
\hline 1978-82 & $1122(16)$ & 680 (15) & $1041(16)$ \\
\hline $1983-88$ & 2019 (29) & $1307(29)$ & $1866(28)$ \\
\hline 1989-94 & $2989(43)$ & $1992(45)$ & $3000(45)$ \\
\hline \multicolumn{4}{|l|}{ Maternal age $(y)$} \\
\hline $15-19$ & $135(2)$ & $63(1)$ & $238(4)$ \\
\hline $20-24$ & $2288(33)$ & $1415(32)$ & 1945 (29) \\
\hline $25-29$ & 2957 (42) & $1929(43)$ & $2735(41)$ \\
\hline $30-34$ & 1312 (19) & $888(20)$ & $1376(21)$ \\
\hline$\geqslant 35$ & $268(4)$ & $170(4)$ & $335(5)$ \\
\hline \multicolumn{4}{|l|}{ Maternal weight $(\mathrm{kg})^{*}$} \\
\hline$<60$ & $572(16)$ & $548(16)$ & $381(16)$ \\
\hline $60-69$ & $1166(33)$ & $1032(30)$ & $732(31)$ \\
\hline 70-79 & $1101(31)$ & $1039(31)$ & $732(31)$ \\
\hline$\geqslant 80$ & $715(20)$ & $766(23)$ & $492(21)$ \\
\hline Unknown & 1701 & 1721 & 1111 \\
\hline \multicolumn{4}{|c|}{ Maternal height $(\mathrm{cm})^{*}$} \\
\hline$<160$ & $529(13)$ & 348 (13) & $499(13)$ \\
\hline $160-164$ & $1223(30)$ & 787 (29) & $1072(28)$ \\
\hline $165-169$ & $1236(30)$ & 814 (30) & 1189 (31) \\
\hline $170-174$ & $901(22)$ & $612(22)$ & $850(22)$ \\
\hline$\geqslant 175$ & $247(6)$ & $167(6)$ & $280(7)$ \\
\hline Unknown & 1119 & 720 & 1216 \\
\hline \multicolumn{4}{|l|}{ Parity } \\
\hline 1 & $4061(58)$ & $2630(59)$ & $3696(56)$ \\
\hline 2 & $2135(31)$ & $1374(31)$ & $1993(30)$ \\
\hline$\geqslant 3$ & $764(11)$ & $461(10)$ & $939(14)$ \\
\hline \multicolumn{4}{|c|}{ Smoking habits in early pregnancy (cigarettes per day)* } \\
\hline 0 & 3529 (73) & $2418(75)$ & $3508(75)$ \\
\hline $1-9$ & $876(18)$ & $532(17)$ & $761(16)$ \\
\hline$\geqslant 10$ & $435(9)$ & $256(8)$ & 425 (9) \\
\hline Unknown & 415 & 242 & 412 \\
\hline
\end{tabular}

after two reminders was $65 \%$ (2410/3706, table 1$)$. The women were asked to state the calendar years of all work periods as a hairdresser from the time they graduated and the hours of work per week for each work period. They also stated whether they were not actively working during periods of more than one year for any reason. "Working as a hairdresser during pregnancy" was defined in accordance with the following: start of work the calendar year before the birth, or earlier; and leaving work at the calendar year of birth, or later. By this definition the responders worked as a hairdresser during $47 \%$ of the studied pregnancies. In addition, questions on exposure during work as a hairdresser were asked for each employment (treatments per week for permanent waving, hair dying, bleaching, shampooing, and spraying).

\section{Characteristics of the cohorts}

The hairdresser differed only marginally from the referents with regard to calendar year of birth, maternal age, height, weight, parity, and smoking habits in early pregnancy (table 1). Moreover, the characteristics were also very similar for the hairdressers who answered the questionnaire and for those who did not. By definition, the majority of hairdressers have the same educational level in the MBR, whereas the referents comprised more women with lower educational level as well as more women with higher educational level (data not shown).

\section{Statistics}

Logistic regression was used to estimate the odds ratio (OR) with respect to cohort affiliation (hairdressers versus referents) on LBW, preterm birth, SGA, stillbirths, END, and malformations, respectively. Multiple births and infants with major malformations were excluded from the analyses regarding LBW, preterm birth, and SGA; as potential confounders we analysed calendar year of birth (1973-77, 1978-82, 1983-88, and 1989-94), maternal age ( $\leqslant 24,25-29$, and $\geqslant 30$ years ), gender, parity ( 1 and $\geqslant 2$ ), maternal weight in early pregnancy $(<60,60-69,70-79$, and $\geqslant 80 \mathrm{~kg})$, maternal height ( <160, 160-164, 165-169, 170-174, and $\geqslant 175 \mathrm{~cm})$, and smoking habits in early pregnancy (non-smokers, 1-9 cigarettes a day, $\geqslant 10$ cigarettes a day, and unknown). In addition, we tested whether these factors modified the effect of exposure. Regarding stillbirths, END and malformations calendar year of birth, maternal age, and parity were analysed as potential confounders. If the adjusted OR differed less than $15 \%$ from the crude OR, we present the crude results. Among 
Table 2 Delivery outcomes among 6960 infants born to 3706 Swedish hairdressers (All) and 6629 infants born to 3462 women from the general population (Referents); delivery outcomes are also presented for the subgroup of hairdressers (Questionnaire; 2410 women) that answered a questionnaire regarding occupational exposure

\begin{tabular}{llll}
\hline & \multicolumn{2}{l}{ Hairdressers } & \\
\cline { 2 - 3 } & All n (\%) & Questionnaire n (\%) & Referents n (\%) \\
\hline Gender (boys) & $3601(51.7)$ & $2317(51.9)$ & $3332(50.3)$ \\
Low birth weight $(<2.5 \mathrm{~kg})$ & $309(4.5)$ & $190(4.3)$ & $274(4.1)$ \\
Preterm birth $(<37$ weeks) & $446(6.4)$ & $281(6.3)$ & $410(6.2)$ \\
Small for gestational age & $247(3.6)$ & $162(3.6)$ & $188(2.9)$ \\
Stillbirths & $29(0.4)$ & $0(0)$ & $26(0.4)$ \\
Early neonatal deaths $(<7$ days) & $23(0.3)$ & $13(0.3)$ & $13(0.2)$ \\
All malformations & $327(4.7)$ & $204(4.6)$ & $290(4.4)$ \\
Major malformations* & $195(2.8)$ & $124(2.8)$ & $142(2.1)$ \\
\hline
\end{tabular}

*Excluding minor malformations such as preauricular appendices, undescended testicles, unstable hip, and nevus.

the hairdressers who had answered the questionnaire the associations between specific exposure and reproductive outcome were analysed in the same manner.

\section{RESULTS}

\section{Birth weight, preterm birth, and SGA}

The median birth weights were $3.48 \mathrm{~kg}$ (quartiles 3.15 and 3.81 ) among infants born to hairdressers and $3.53 \mathrm{~kg}$ (quartiles 3.17 and 3.86) among the referent infants. The hairdressers had a higher incidence of infants with LBW compared with the referents (4.5\% versus $4.1 \%$; OR $1.2,95 \%$ CI 1.0 to 1.5 , tables 2 and 3), whereas no obvious differences were seen regarding preterm birth. There was a higher fraction of intrauterine growth retarded infants (that is, SGA) in the hairdressers' cohort than among the referents $(3.6 \%$ versus 2.9\%; OR $1.4,95 \%$ CI 1.1 to 1.7 ).

An association was indicated between the number of weekly work hours as a hairdresser and LBW. The hairdressers who worked more than 30 hours per week during pregnancy had an LBW infant more frequently than hairdressers with less working hours per week (OR 1.8, 95\% CI 1.0 to 3.3, table 4). Moreover, permanent waving tended to be associated with LBW and SGA, shampooing with LBW, and spraying with SGA (table 4).

\section{Stillbirths and END}

The fractions of stillbirths were similar in both cohorts, whereas there was a somewhat increased fraction of END among the hairdressers $(0.3 \%$ versus $0.2 \%$; OR $1.7,95 \%$ CI 0.9 to 3.3, tables 2 and 5). There was no obvious difference of the sum of stillbirths and END between the cohorts (OR 1.3, 95\% CI 0.8 to 1.9 , not in table). Because of the small number of cases, no further analyses were done with regard to specific exposures within the cohort of hairdressers.

\section{Malformations}

The fractions among the newborns who had a major malformation were $2.8 \%$ in the cohort of hairdressers and $2.1 \%$ among the referents corresponding to an OR of $1.3(95 \%$ CI 1.1 to 1.6 , tables 2 and 5). None of the individual exposures showed any clear positive associations with the outcome major malformation. However, hairdressers who during pregnancy had performed more than 30 treatments of spraying per week tended to have fewer infants with major malformations compared with hairdressers with less treatments (OR 0.6, 95\% CI 0.3 to $1.0, p=0.07$, not in table). Table 6 presents the numbers of some specific malformations within the cohort of hairdressers.

\section{Gender ratio}

The fraction of boys in the hairdressers' cohort was 51.7\% ( $95 \%$ CI 50.6 to 52.9 ) corresponding to a gender ratio (number of boys/number of girls) of 1.07 (table 2). The corresponding figures among the referents were $50.3 \%$ (95\% CI 49.0 to 51.5 ) and 1.01. In the overall Swedish population the gender ratio is $1.06 .^{18}$

Table 3 Risk of having an infant with $\mathrm{LBW}(<2.5 \mathrm{~kg})$, preterm birth $(<37$ weeks), or SGA among 6960 newborn infants in a cohort of Swedish hairdressers compared with 6629 newborn infants in a cohort of women from the general population (Referents)

\begin{tabular}{|c|c|c|c|c|c|c|c|c|c|}
\hline \multirow[b]{3}{*}{ Cohort } & \multicolumn{9}{|c|}{ Outcome } \\
\hline & \multicolumn{3}{|c|}{$1973-82$} & \multicolumn{3}{|c|}{ 1983-94 } & \multicolumn{3}{|c|}{$1973-94$} \\
\hline & OR & $95 \% \mathrm{Cl}$ & $\mathrm{p}$ & OR & $95 \% \mathrm{Cl}$ & $p$ & OR & $95 \% \mathrm{Cl}$ & $\mathrm{p}$ \\
\hline \multicolumn{10}{|l|}{ LBW } \\
\hline Referents & 1.0 & & & 1.0 & & & 1.0 & & \\
\hline Hairdressers & 1.4 & 0.9 to 2.0 & 0.10 & 1.2 & 0.9 to 1.4 & 0.23 & 1.2 & 1.0 to 1.5 & 0.06 \\
\hline \multicolumn{10}{|l|}{ Preterm birth } \\
\hline Referents & 1.0 & & & 1.0 & & & 1.0 & & \\
\hline Hairdressers & 1.2 & 0.9 to 1.7 & 0.21 & 1.0 & 0.9 to 1.2 & 0.64 & 1.1 & 0.9 to 1.3 & 0.30 \\
\hline \multicolumn{10}{|l|}{ SGA } \\
\hline Referents & 1.0 & & & 1.0 & & & 1.0 & & \\
\hline Hairdressers & 1.5 & 1.0 to 2.1 & 0.03 & 1.3 & 1.0 to 1.7 & 0.06 & 1.4 & 1.1 to 1.7 & 0.004 \\
\hline
\end{tabular}


Table 4 Risk of having an infant with LBW ( $<2.5 \mathrm{~kg}$ ), preterm births ( $<37$ weeks), or SGA in relation to different exposures among 4465 newborn infants in a cohort of Swedish hairdressers

\begin{tabular}{|c|c|c|c|c|c|c|c|c|c|c|}
\hline \multirow[b]{2}{*}{ Exposure } & \multirow[b]{2}{*}{$\%$} & \multicolumn{3}{|l|}{ LBW } & \multicolumn{3}{|c|}{ Preterm } & \multicolumn{3}{|l|}{ SGA } \\
\hline & & OR & $95 \% \mathrm{Cl}$ & $\mathrm{p}$ & OR & $95 \% \mathrm{Cl}$ & $\mathrm{p}$ & OR & $95 \% \mathrm{Cl}$ & $\mathrm{p}$ \\
\hline \multicolumn{11}{|c|}{ Working as a hairdresser during pregnancy } \\
\hline No & 53 & 1.0 & & & 1.0 & & & 1.0 & & \\
\hline Yes & 47 & 1.2 & 0.9 to 1.7 & 0.22 & 1.1 & 0.8 to 1.4 & 0.47 & 0.8 & 0.6 to 1.2 & 0.34 \\
\hline \multicolumn{11}{|c|}{ Hours of work per week } \\
\hline$\leqslant 30$ & 30 & 1.0 & & & 1.0 & & & 1.0 & & \\
\hline$>30$ & 70 & 1.8 & 1.0 to 3.3 & 0.06 & 1.3 & 0.8 to 2.0 & 0.30 & $1.8 \dagger$ & 0.7 to 4.8 & 0.23 \\
\hline \multicolumn{11}{|c|}{ Permanent waving* } \\
\hline $0-1$ & 62 & 1.0 & & & 1.0 & & & 1.0 & & \\
\hline$\geqslant 2$ & 38 & $1.9 \dagger$ & 0.9 to 4.0 & 0.09 & 1.1 & 0.7 to 1.6 & 0.77 & $1.9 \dagger$ & 0.9 to 4.2 & 0.11 \\
\hline \multicolumn{11}{|c|}{ Hair dying* } \\
\hline $0-1$ & 42 & 1.0 & & & 1.0 & & & 1.0 & & \\
\hline$\geqslant 2$ & 58 & 0.7 & 0.5 to 1.2 & 0.25 & 1.1 & 0.6 to 1.6 & 0.71 & 0.8 & 0.4 to 1.4 & 0.41 \\
\hline \multicolumn{11}{|c|}{ Hair bleaching* } \\
\hline $0-1$ & 34 & 1.0 & & & 1.0 & & & 1.0 & & \\
\hline$\geqslant 2$ & 66 & 0.9 & 0.5 to 1.4 & 0.57 & 0.9 & 0.6 to 1.3 & 0.45 & $1.6 \dagger$ & 0.6 to 4.1 & 0.32 \\
\hline \multicolumn{11}{|c|}{ Shampooing* } \\
\hline$\leqslant 30$ & 43 & 1.0 & & & 1.0 & & & 1.0 & & \\
\hline$>30$ & 57 & 1.5 & 0.9 to 2.6 & 0.11 & 1.5 & 1.0 to 2.3 & 0.05 & 1.1 & 0.7 to 2.0 & 0.63 \\
\hline \multicolumn{11}{|l|}{ Spraying* } \\
\hline$\leqslant 30$ & 33 & 1.0 & & & 1.0 & & & 1.0 & & \\
\hline$>30$ & 67 & 1.3 & 0.8 to 2.4 & 0.31 & 1.3 & 0.8 to 2.0 & 0.30 & $2.3 \ddagger$ & 0.9 to 6.1 & 0.09 \\
\hline
\end{tabular}

\section{DISCUSSION}

The main finding of the present study was an increased risk among Swedish hairdressers of having infants being small for gestational age compared with women from the general Swedish population. In addition, the hairdressers' infants had a higher incidence of major malformations.

Information on the outcome variables are based on data from the MBR. The quality of birth weight data has been judged as good, whereas it is more difficult to get a good estimation of gestational length. ${ }^{15}$ It is, however, reasonable to believe that the estimations of gestational length were most likely affected by non-differential errors. Such misclassification tends to produce an underestimation of the actual risk. ${ }^{19}$

The MBR includes most infants born in Sweden since 1973. ${ }^{15}$ Thus, it is not reasonable to believe that selection bias was present when comparisons were performed between the cohorts of hairdressers and the referents. The fraction of hairdressers who answered the questionnaire was only $65 \%$, which in principle might lead to selection bias affecting the exposure effects. However, the distributions of the background

\begin{tabular}{|c|c|c|c|}
\hline \multirow[b]{2}{*}{ Cohort } & \multicolumn{3}{|c|}{ Outcome } \\
\hline & OR & $95 \% \mathrm{Cl}$ & $\mathrm{p}$ \\
\hline \multicolumn{4}{|l|}{ Stillbirths } \\
\hline Referents & 1.0 & - & \\
\hline Hairdressers & 1.1 & 0.6 to 1.8 & 0.82 \\
\hline \multicolumn{4}{|c|}{ Early neonatal death $(<7 \text { days })^{*}$} \\
\hline Referents & 1.0 & - & \\
\hline Hairdressers & 1.7 & 0.9 to 3.3 & 0.13 \\
\hline \multicolumn{4}{|l|}{ All malformations } \\
\hline Referents & 1.0 & - & \\
\hline Hairdressers & 1.1 & 0.9 to 1.3 & 0.37 \\
\hline \multicolumn{4}{|c|}{ Major malformation $\dagger$} \\
\hline Referents & 1.0 & - & \\
\hline Hairdressers & 1.3 & 1.1 to 1.6 & 0.01 \\
\hline
\end{tabular}

*Stillbirth excluded from the analysis.

†Excluding minor malformations such as preauricular appendices, undescended testicles, unstable hip, and nevus. 
Table 6 Some specific major malformation diagnoses among 6960 newborn infants in a cohort of Swedish hairdressers

\begin{tabular}{lr}
\hline Malformation & $\mathrm{n}$ \\
\hline Spina bifida & 5 \\
Hydrocephalus & 6 \\
Cleft palate & 2 \\
Cleft lip/palate & 12 \\
Heart defects & 46 \\
Ventricle septal defect (VSD) & 15 \\
Patent ductus arteriosus & 2 \\
Hypoplastic left heart syndrome (HLHS) & 2 \\
Atrial septum defect & 1 \\
Aortic valve stenosis & 1 \\
Transposition of great vessels & 1 \\
Common truncus & 1 \\
Coarctation aorta + VSD & 1 \\
Unspecified & 22 \\
Oesophagus/anal atresia & 3 \\
Omphalocoele & 1 \\
Bladder extrophy & 1 \\
Hypospadias & 11 \\
Polydactyly & 5 \\
Syndactyly & 9 \\
Limb reduction & 4 \\
Talipes & 24 \\
Down's syndrome & 7 \\
Other chromosomal abnormalities & 3 \\
Multiple malformation & \\
Microcephaly + cystic kidney & 1 \\
Cleft lip/palate + heart defect (HLHS/Fallot/ & 3 \\
unspecified) & \\
Heart defect (single ventricle + coarctation aorta) + & 1 \\
spine malformation + micrognathia & \\
Cleft palate + severe ear malformation & 1 \\
Anal atresia + choanal atresia & 1 \\
Anal atresia + hypospadias & 1 \\
Anal atresia + kidney dysgenesis + cloacal \\
malformation + absent genital organ + sacral agenesis & 1 \\
Anal atresia + oesophagus atresia + kidney agenesis & 1 \\
Severe kidney malformation + syndactyly & 1 \\
\hline & \\
& \\
& \\
& \\
& \\
&
\end{tabular}

characteristics were very similar among the hairdressers who had answered the questionnaire and the other hairdressers. Moreover, with the exception of stillbirths, the distributions of the outcome variables were also very similar for the responders and non-responders. We do not therefore believe that selection bias is an issue of major concern.

Maternal age, parity, gender of the infant, maternal weight and height, and smoking habits are all known factors affecting the birth weight of an infant. ${ }^{18}$ When these factors were considered as potential confounders in the comparisons performed between the cohort of hairdressers and the referents, the effect estimates regarding LBW and SGA only changed marginally. In addition, these factors did not modify the effect of exposure. Consideration of these potential confounders did not change the effect estimates for major malformations. Thus, the findings in the present study cannot be disregarded as a result of confounding from these factors. Information about other potential confounders, such as the women's alcohol consumption and the spouse's age and height, were not obtained. Therefore, whether the distributions for these factors differed between the cohorts remains unknown.

For LBW, similar results were seen in a cohort study performed in the Netherlands by Kersemeakers et al, where reproductive disorders were compared between hairdressers and clothing sale clerks. ${ }^{20}$ Their study indicated an increased risk of having an infant with LBW among hairdressers' infants conceived between 1986 and 1988. This negative effect seemed, however, to disappear during a later period (199193). In the present study, calendar year did not modify the observed effect on LBW.

\section{Main messages}

- Compared with women from the general population, hairdressers more often gave birth to growth retarded infants.

- A slightly higher fraction of infants born to hairdressers had a major malformation.

- Frequent permanent waving and spraying tended to be associated with increased risk of having a growth retarded infant.

- No increased risk was found for individual exposure assessments and major malformations.

\section{Policy implications}

- Regular use of protective gloves, especially during pregnancy.

- Installation of exhaust ventilation in the mixing areas, and improvement of the general ventilation in the salons.

In the Netherlands study major malformations had occurred more frequently among infants of hairdressers, but the numbers were small. ${ }^{20}$ In a recent multicentre study investigating the association between maternal exposure at work and cleft lip/palate, hairdressers had an increased risk for cleft palate. ${ }^{21}$ This result was also based on small numbers. In another recent study, Martínez-Frías et al found an increased risk for choanal atresia among children born to hairdressers. ${ }^{22}$ Although the present study comprised a relatively large number of infants with malformations, the figures were still insufficient to allow comparisons with regard to specific malformations. Moreover, cleft lip and cleft lip/palate as isolated diagnoses are relatively rare events. Based on statistics for Sweden during the period 1983-92, the frequencies were 5.8 and 10.5 per 10000 newborns, respectively. The figures among infants born to hairdressers in the present study were 2.9 and 17.2 per 10000 , respectively. For choanal atresia we observed one infant born to a hairdresser with a multiple malformation including this diagnosis. Thus, the associations observed in the other studies were not clearly supported by our results. In general, regarding specific malformations, when small or moderate risk increases are suspected, multicentre studies are required.

Infants born to hairdressers who reported frequent spraying and permanent waving, respectively, were more likely to be intrauterine growth retarded. Hairspray contains a mixture of components. Among these, ethanol and acetone have occasionally been associated with reduced birth weight, ${ }^{618}$ but data from a Dutch study indicated that considered separately, the concentrations of these agents in hair salons are too low to explain adverse effects on reproduction. ${ }^{123}$ However, possible interactions in the complex exposure situation among hairdressers should also be considered. Furthermore, prolonged bending, standing positions, and work related stress, which we did not consider in this study, may affect intrauterine growth. ${ }^{24} 25$

Within the cohort of hairdressers, none of the individual exposure estimates indicated an association with major malformations. The reliability of self reported exposures for bleaching and spraying among the hairdressers was examined by comparing answers in the present study to those given three years later in a subsample of the cohort. The answers were given in predefined categories in the present study and in absolute numbers in the second questionnaire. The reliability (agreement of response for the same retrospective period between the two questionnaires) was fair for bleaching (kappa value 0.24) and poor for spraying (kappa value 0.17), and thus misclassification of exposure may have introduced a bias which is most likely negative. ${ }^{26}$ 
To summarise, the present study indicates that working as a hairdresser is associated with a moderately increased risk for retarded intrauterine growth and major malformations, although no consistent patterns were seen with regard to spe-

cific agents. Studies of other reproductive outcomes, such as decreased fertility and miscarriages, are in progress.

\section{ACKNOWLEDGEMENTS}

The study was funded by the Swedish Council for Work Life Research and by the Medical Faculty, Lund University. The authors thank Zoli Mikoczy, Birgitta Meding, Jonas Brisman, Linnea Lillienberg, and Anna Dahlman for their help with establishing the cohort, and Lars Hagmar for fruitful discussions.

\section{Authors' affiliations}

L Rylander, A Axmon, M Albin, Department of Occupational and Environmental Medicine, Institute of Laboratory Medicine, University Hospital, SE-221 85 Lund, Sweden

K Torén, Institute of Internal Medicine, Section of Occupational Medicine, Sahlgrenska University Hospital, SE-412 66 Gothenburg, Sweden

\section{REFERENCES}

1 Kersemaekers WM, Roeleveld N, Zielhuis GA. Reproductive disorders due to chemical exposure among hairdressers. Scand J Work Environ Health 1995:21:325-34.

2 Casarett and Doull. Toxicology. The basic science of poisons. New York: Pergamon Press, 1993.

3 Schardein JL. Chemically induced birth defects. New York: Marcel Dekker, Inc., 1985

4 Inouye M, Murakami U. Teratogenicity of 2,5-diaminotoluene, a hair dye constituent, in mice. Fd Cosmet Toxicol 1977;15:447-51.

5 Marks TA, Gupta BN, Ledoux TA, et al. Teratogenic evaluation of 2-nitro-p-phenylenediamine, 4-nitro-o-phenylediamine, and 2,5-toluenediamine sulfate in the mouse. Teratology 1981;24:253-65.

6 Commission of the European Communities. Reproductive toxicity: the toxicology of chemicals, series two. Luxembourg: EEC, 1993

7 Ikeda I. Public health problems of organic solvents. Toxicol Lett 1992;64-65: 191-201.

8 Cohen AJ, Roe FJC. Review of lead toxicity relevant to the safety assessment of lead acetate as a hair colouring. Fd Chem Toxic $1991 ; 29: 485-507$
9 Huel G, Mergler D, Bowler R. Evidence for adverse reproductive outcomes among microelectronic assembly workers. BrJ Ind Med 1990; 7:400-4

10 Lipscomb JA, Fenster L, Wrensch M, et al. Pregnancy outcomes in women potentially exposed to occupational solvents and women working in the electronics industry. J Occup Med 1991;33:597-604.

11 Preston-Martin S, Yu MC, Benton B, et al. N-nitroso compounds and childhood brain tumors: a case control study. Cancer Res 1982;42:5240-5

12 Barlow SM, Sullivan FM. Reproductive hazards of industrial chemicals. An evaluation of animal and human data. London: Academic Press, 1982.

13 Roeleveld N. Mental retardation and parental occupation: an explorative epidemiologic study. Dissertation. Nijmegen: University of Nijmegen, 1991.

14 International Agency for Research on Cancer. Occupational exposures of hairdressers and barbers and personal use of hair colourants; some hair dyes, cosmetic colourants, industrial dyestuffs and aromatic amines. IARC monographs on the evaluation of carcinogenic risks to humans, Vol. 57. Lyon: IARC, 1993.

15 Cnattingius S, Ericson A, Gunnarskog J, et al. A quality study of a medical birth registry. Scand J Soc Med 1990;18:143-8.

16 Ericson A, Källén B, Winberg J. Surveillance of malformations at birth: a comparison of two record systems run in parallel. Int J Epidemiol 1977;6:35-41

17 Källén B. A birth weight for gestational age standard based on data in the Swedish medical birth registry, 1985-1989. Eur J Epidemiol 1995;11:601-6.

18 Källén B. Epidemiology of human reproduction. Boca Raton, FL: CRC Press, 1988.

19 Wacholder S, Hartge P, Lubin JH, et al. Non-differential misclassification and bias towards the null: a clarification. Occup Environ Med 1995:52:557-8.

20 Kersemaekers Roeleveld N, Zielhuis GA. Reproductive disorders among hairdressers. Epidemiology 1997;8:396-401.

21 Lorente C, Cordier S, Bergeret A, et al. Maternal occupational risk factors for oral cleft. Scand J Work Environ Health 2000;26:137-45.

22 Martínez-Frías ML, Bermejo E, Rodríguez-Pinilla E, et al. Case-control study of occupation as hairdresser during pregnancy and congenital defects. Environ Epidemiol Toxicol 2000;2:20-3.

23 Muiswinkel WJ, Kromhout $\mathrm{H}$, Onos T, et al. Monitoring and modelling of exposure to ethanol in hairdressing salons. Ann Occup Hyg 1997:41:235-47.

24 Ahlborg U. Physical work load and pregnancy outcome. J Occup Environ Med 1995;37:941-4

25 Lindbohm ML. Women's reproductive health: some recent developments in occupational epidemiology. Am J Ind Med 1999;36:18-24.

26 Albin M, Rylander L, Mikoczy Z, et al. Incidence of asthma in female Swedish hairdressers. Occup Environ Med 2002;59:1 19-23. 